\title{
Impact of prescribed SSTs on climatologies and long-term trends in CCM simulations
}

\author{
H. Garny, M. Dameris, and A. Stenke \\ Deutsches Zentrum für Luft- und Raumfahrt (DLR), Institut für Physik der Atmosphäre, Oberpfaffenhofen, Germany \\ Received: 22 December 2008 - Published in Atmos. Chem. Phys. Discuss.: 23 February 2009 \\ Revised: 5 May 2009 - Accepted: 12 August 2009 - Published: 20 August 2009
}

\begin{abstract}
Chemistry-Climate Model (CCM) simulations are commonly used to project the past and future development of the dynamics and chemistry of the stratosphere, and in particular the ozone layer. So far, CCMs are usually not interactively coupled to an ocean model, so that sea surface temperatures (SSTs) and sea ice coverage are prescribed in the simulations. While for future integrations SSTs have to be taken from precalculated climate model projections, for CCM experiments resembling the past either modelled or observed SSTs can be used. This study addresses the question to which extent atmospheric climatologies and long-term trends for the recent past simulated in the CCM E39C-A differ when choosing either observed or modelled SSTs. Furthermore, the processes of how the SST signal is communicated to the atmosphere, and in particular to the stratosphere are examined. Two simulations that differ only with respect to the prescribed SSTs and that span years 1960 to 1999 are used.

Significant differences in temperature and ozone climatologies between the model simulations are found. The differences in ozone are attributed to differences in the meridional circulation, which are in turn driven by weaker wave forcing in the simulation with generally lower SSTs. The long-term trends over 40 years in annual mean temperature and ozone differ only in the troposphere, where temperatures are directly influenced by the local SST trends. Differences in temperature and ozone trends are only found on shorter time scales. The trends in tropical upwelling, as a measure of the strength of the Brewer-Dobson circulation (BDC), differ strongly between the simulations. A reverse from negative to positive trends is found in the late 1970s in the simulation using observed SSTs while trends are positive throughout the
\end{abstract}

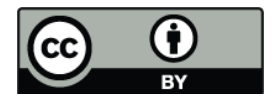

Correspondence to: H. Garny (hella.garny@dlr.de) simulation when using modelled SSTs. The increase in the BDC is a robust feature of the simulations only after about 1980 and is evident mainly in the tropics in the lower stratosphere.

\section{Introduction}

Chemistry-Climate Models (CCMs) were used extensively in the last decade to study the evolution of the global ozone layer and to identify processes leading to changes in ozone in the past and future. For the World Meteorological Organization's scientific assessments of ozone depletion (e.g. WMO, 2007) and as a part of the SPARC CCM Validation Activity CCMVal (Eyring et al., 2005; Eyring et al., 2008), common model strategies have been defined including transient simulations designed to closely resemble the past ("REF1") and to predict possible future developments of the ozone layer ("REF2" and "SCN2", without and with including natural variability, namely the QBO and the 11year solar cycle). While in REF1, the boundary conditions including natural and anthropogenic variability are mainly deduced from observations, the REF2 or SCN2 scenarios are subjected to the use of future projections of the development of the boundary conditions. As lower boundary condition, sea surface temperatures (SSTs) and sea ice coverage are prescribed to the CCM simulations. For the REF2/SCN2 scenarios, these are commonly taken from climate model projections that include an interactively coupled ocean (i.e. atmosphere ocean general circulation models, AOGCM). The modelled atmosphere-ocean system differs from reality due to both model deficits and non-deterministic internal variability (see e.g. Meehl et al., 2007; Newman, 2007). Therefore, climatologies and the temporal evolution of SSTs from AOGCMs differ from SSTs deduced from observations. This

Published by Copernicus Publications on behalf of the European Geosciences Union. 
raises the question of how CCM simulations are affected by the SST differences introduced by using modelled instead of observed SSTs.

The modelled stratosphere is known to be highly sensitive to the prescribed SSTs. For example, Braesicke and Pyle (2004) studied the impact of inter-annual variability in SSTs by comparing a simulation with long-term mean SSTs to a simulation with transient SSTs. The results showed that the variability in SSTs can act to induce ozone trends in the stratosphere due to a modification of the wave activity flux entering the stratosphere.

Various studies analysed the impact of the El NiñoSouthern Oscillation (ENSO) on the stratosphere (Manzini et al., 2006; Sassi et al., 2004; Yulaeva and Wallace, 1994; Clarke and Kim, 2005; García-Herrera et al., 2006). The results generally suggest that the ENSO signal is communicated to the stratosphere by planetary wave modulation and subsequent changes in the mean meridional circulation. For example García-Herrera et al. (2006) and Hardiman et al. (2007) show positive correlations between ENSO indices and tropical upwelling, indicating stronger planetary wave fluxes and therefore a stronger meridional circulation in ENSO warm phases and vice versa in ENSO cold phases.

Recently, a connection between SSTs and the lower stratosphere was suggested for the tropical regions (Deckert and Dameris, 2008a,b; Rosenlof and Reid, 2008). In Deckert and Dameris (2008a), SSTs were linked to tropical upwelling via wave generation by deep convection, implying that tropical upwelling is sensitive to changes in SSTs. While this study is based on CCM simulations, similar evidence of a linkage between tropical SSTs and the lower stratosphere was found from radiosonde observational data by Rosenlof and Reid (2008). The issue of predicted changes in tropical upwelling (as the tropical branch of the Brewer-Dobson Circulation) in a changing climate was addressed frequently in the recent past (e.g. Butchart et al., 2006), but the reasons for changes are still largely unknown. If SSTs can act as a driver of upwelling, predicted changes of the Brewer-Dobson Circulation (BDC) might be strongly affected by the use of different SST data.

In this study, two CCM simulations starting in 1960 and corresponding to the REF1 and SCN2 scenarios, respectively, are compared. For the period 1960 to 1999, both simulations use the same boundary conditions except for the SSTs (including sea ice coverage; in the following, the term SSTs always includes sea ice coverage). Consequently the comparison of these simulations can give an estimate of the differences introduced in the CCM simulation by using different SST data. Since for future predictions only modelled SSTs can be used, the issue of how the SST differences between observed and modelled data sets affect both the climatological mean state and trends and variability of the modelled atmosphere is highly relevant to assess the uncertainty of future projections. For example, when comparing a past period of the REF1 simulation with a future period from REF2/SCN2, one has to be aware of the fact that the changing pattern is a superimposition of changes due to changing boundary conditions with time ("climate change"), and differences due to the use of a different SST data basis. Since the real future development of SSTs is unknown, we can refer only to the past to obtain a rough idea of the quantity of uncertainties due to model deficits in capturing the real SST development. Apart from that, the comparison of the two model simulations can reveal insights in the processes of how SSTs act to influence the atmosphere, and in particular the stratosphere, which we focus on in this study.

The paper is structured as follows. After a brief model description and a discussion on the SSTs in Sect. 2, some methods used in the analyses are given in Sect. 3. Section 4 compares the climatological mean state of the REF1 and SCN2 model simulation, while in Sect. 5 differences in the longterm evolution are investigated.

\section{Model description and SSTs}

In this study, the CCM ECHAM4.L39(DLR)/CHEM/ ATTILA (E39C-A) is used. The model is an updated version of ECHAM4.L39(DLR)/CHEM (E39C) (Hein et al., 2001; Dameris et al., 2005) with the former semi-Lagrangian advection scheme replaced by the fully Lagrangian advection scheme ATTILA (Reithmeier and Sausen, 2002). The use of the fully Lagrangian advection scheme ATTILA for tracertransport improved the model performance substantially (Stenke et al., 2008; Stenke et al., 2009). E39C is based on the spectral general circulation model ECHAM4.L39(DLR) (Land et al., 2002) and the chemistry-module CHEM (Steil et al., 1998). The spectral horizontal resolution of the model is $\mathrm{T} 30$, corresponding to approximately $3.75^{\circ} \times 3.75^{\circ}$ on the transformed latitude-longitude grid. In the vertical, the model consists of 39 layers, extending from the surface to the uppermost layer which is centred at $10 \mathrm{hPa}$. The chosen time step is $24 \mathrm{~min}$. The chemistry module CHEM is based on a generalised family concept and includes homogeneous and stratospheric heterogeneous ozone chemistry and the most relevant chemical processes for describing the tropospheric background chemistry. For more details on E39CA, see Stenke et al. (2009).

The experimental set-up of the two transient simulations used in this study correspond to the REF-B1 and SCN-B2d scenarios as defined for the next WMO ozone assessment (Eyring et al., 2008). The REF1 simulation used here is the same as described in detail in Stenke et al. (2009). Briefly, the external forcings defined as boundary conditions are the 11-year solar cycle, the quasi-biennial oscillation, sulphate aerosol loadings and radiative effects of major volcanic eruptions (namely Agung, El Chichón and Mount Pinatubo), the loading of ozone depleting substances, greenhouse gas concentrations and natural as well as anthropogenic $\mathrm{NO}_{\mathrm{x}}$ emissions. 
The SSTs in the REF1 simulation are prescribed as monthly means following the updated global sea ice coverage and sea surface temperature data set HadISST1 provided by the UK Met Office Hadley Center (Rayner et al., 2003). Following a 10-year spin-up period, the simulation spans the time period 1960 to 2004.

The SCN2 experiment, which spans years 1960 to 2049, is set up in exactly the same way as the REF1 simulation for years 1960-1999 except for the prescribed SSTs. After 1999, the boundary conditions for the SCN2 simulation follow future scenarios, so that years 2000 to 2004 of REF1 do not correspond to the same years in SCN2 (e.g. in terms of phase of the solar cycle). Therefore, the paper will focus on the years 1960 to 1999 only. Instead of the HadISST1 data set, SSTs and sea ice in SCN2 are taken from the HadGEM1 general circulation model (Martin et al., 2006; Johns et al., 2006). The SSTs for 1960 to 1999 are from the HadGEM1 transient simulation with anthropogenic forcing only (Stott et al., 2006, "ANTHRO" in their Table 1), i.e. excluding volcanic eruptions and the solar cycle. The future SST projections used for SCN2 (years 2000 to 2049) are from the SRES A1B run of HadGEM1, which is initiated from ANTHRO so that a consistent SST data set is obtained. These HadGEM1 simulations are part of the World Climate Research Programme's (WCRP's) Coupled Chemistry Climate Intercomparison Project phase 3 (CMIP-3) multimodel dataset used for the 4th Intergovernmental Panel on Climate Change (IPCC) Assessment Report and were provided by the Program for Climate Model Diagnosis and Intercomparison (PCMDI, available at: http://www-pcmdi.llnl.gov).

After the initial spin-up period of 10 years in both simulations the equilibrium state is reached sufficiently well so that all variability and trends after 1960 are either forced by the prescribed boundary conditions or are due to internal variability of the atmospheric system. This is verified with water vapour at the uppermost model level $(10 \mathrm{hPa})$, which shows an adjustment time to the underlying SSTs of about 6-7 years (not shown).

A comparison of the HadGEM1 and HadISST SST climatologies is shown in Fig. 1 (see also Johns et al., 2006). The difference pattern is dominated by lower SSTs in HadGEM1 in the tropics, the subtropics and northern mid-latitudes, where the differences are up to $3 \mathrm{~K}$. Smaller regions of higher SSTs in HadGEM1 are found on the west coasts of South America and Africa, as well as on the east coasts of North America and Asia in northern winter (i.e. the storm track regions). There are also large differences in sea ice extent, with generally more sea ice in HadGEM1. Time series of anomalies of global and hemispheric mean SSTs from HadISST and HadGEM1 are compared in Fig. 2. Both the global mean and Southern Hemisphere mean SSTs show generally rather constant values in the 1960s, and rising SSTs since about the mid-1970s. However, in the Northern Hemisphere the SST data set deduced from observations show generally higher SSTs in the 1960s, a strong decrease in the 1970s and rising

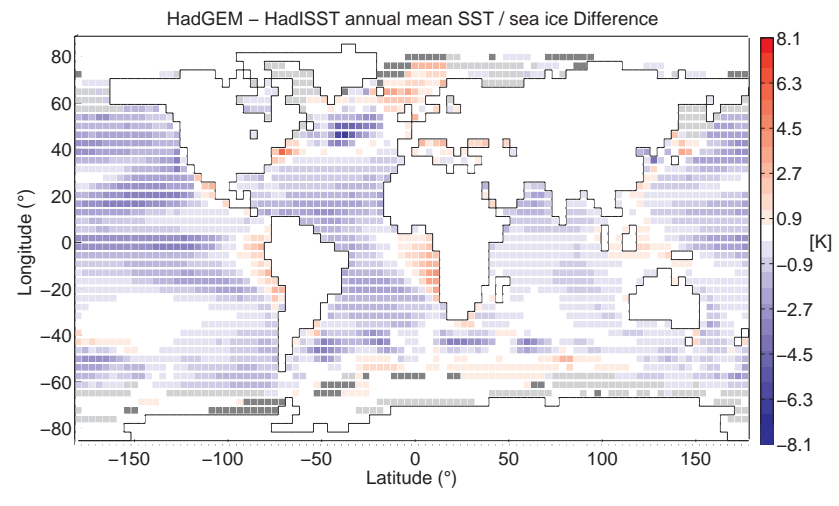

Fig. 1. Difference of 1960 to 1999 annual mean sea surface temperatures [in K] from HadGEM minus HadISST. Differences in sea ice extend are shown in grey, where light grey areas correspond to more sea ice in HadGEM compared to HadISST, and dark grey regions to less sea ice in HadGEM.

temperatures only after the late 1970s. The modelled time series does not reproduce this behaviour, here SST anomalies are negative throughout the 1960s. In terms of variability, the interannual variance due to the El Niño-Southern Oscillation (ENSO) is underestimated and the ENSO signal is too regular in the HadGEM1 model, as shown in Fig. 3 (see also Johns et al., 2006). A detailed study of annual and decadal variability of SST eigenmodes from both observations and several GCMs including HadGEM1 revealed large deficits of the models to capture the variability, and showed that the patterns are less persistent than in reality (Newman, 2007).

\section{Methods of data analyses}

\subsection{Trend calculations and tests on significance}

In the following, both differences between climatologies (i.e. mean values) and long-term changes are analysed. The statistical significance of differences is tested with the StudentT-test (see e.g. von Storch and Zwiers, 2002). To quantify long-term changes, trends are calculated by applying a linear least squares fit of the time series $y(t)$ to a linear function (i.e. $\widehat{y}(t)=a+b t(t=1 \ldots N)$, where $N$ is the number of timesteps). The uncertainty in the trend (i.e. the slope of the linear function $b$ ) is then given by $\sigma^{2}=\frac{\chi^{2}}{N-2} \frac{1}{S_{t t}}$ where $\chi^{2}$ is the sum of the squared residuals $\left(\chi^{2}=\sum_{t=1}^{N}[y(t)-\widehat{y}(t)]^{2}\right)$ and $S_{t t}=\sum_{t=1}^{N} t^{2}-N\left(\frac{N+1}{2}\right)^{2}$. The trend is statistical significant if the null-hypothesis $b=0$ can be rejected, which is tested by comparing the T-test value $t=b / \sigma$ against the critical value of the T-distribution with $N-2$ degrees of freedom.

\subsection{Eliassen-Palm fluxes}

As a measure of wave activity, Eliassen-Palm (EP) fluxes were calculated using the full ageostrophic form 


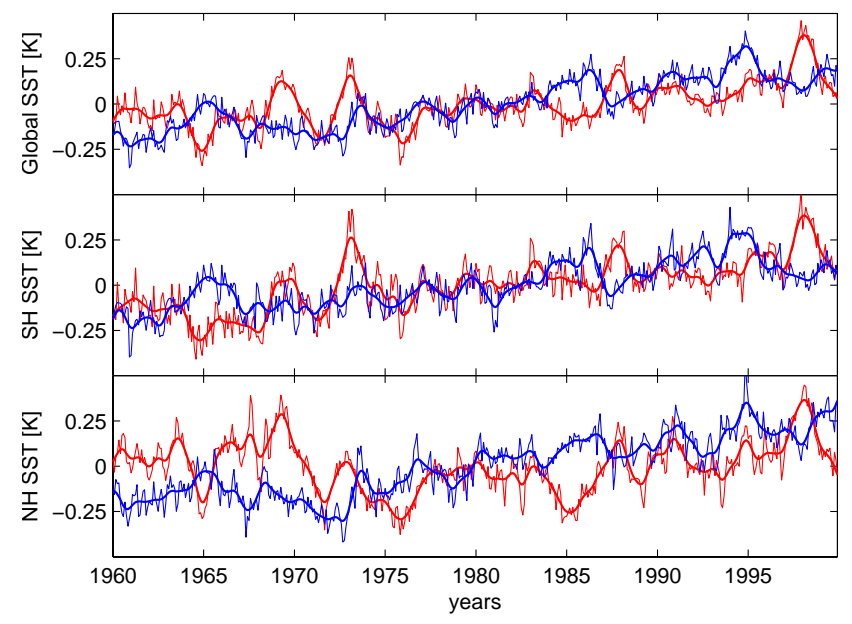

Fig. 2. SST time series with the 1960-1999 mean annual cycle subtracted for REF1 (red) and SCN2 (blue) for global (top), Southern (middle) and Northern (bottom) Hemisphere means. The thick solid lines are smoothed time series (by applying a 1-2-1 filter 20 times).

(e.g. Andrews et al., 1987). The fluxes were scaled by the mass of an annular ring of a certain latitude band and pressure interval (see Edmon et al., 1980, their Eq. 3.12). Using pressure coordinates, the EP flux $\boldsymbol{F}$ at latitude $\phi$ and pressure level $p$ is then given by:

$$
\begin{aligned}
\boldsymbol{F}(\phi, p)= & 2 \pi r_{e} \cos (\phi) / g \times \\
& {\left[r_{e} \cos (\phi)\left(-\overline{u^{\prime} v^{\prime}}+\frac{\overline{v^{\prime} \Theta^{\prime}}}{\Theta_{p}} u_{p}\right),\right.} \\
& \left.r_{e}^{2} \cos (\phi)\left(\left(f-u_{\phi}\right) \frac{\overline{v^{\prime} \Theta^{\prime}}}{\Theta_{p}}-\overline{u^{\prime} \omega^{\prime}}\right)\right]
\end{aligned}
$$

where $r_{e}$ is the Earth's radius, $g$ the gravitational constant, $\Theta$ the potential temperature and $f=2 \Omega \sin (\phi)$ the Coriolis parameter ( $\Omega$ is the Earth's angular speed of rotation). Subscripts denote the partial derivative of the variable. The EP divergence is then $\nabla \cdot \mathbf{F}=\partial F_{\phi} / \partial \phi+\partial F_{p} / \partial p$. Due to the mass scaling, the EP flux is in units $\left[\mathrm{m}^{3}, \mathrm{~m}^{3} \mathrm{~Pa}\right]$ and the divergence in $\left[\mathrm{m}^{3}\right]$, which equals $\mathrm{Nm} / \mathrm{Pa}$, i.e. energy/pressure (Edmon et al., 1980). Both stationary and transient waves are accounted for in the calculation.

\subsection{Tropical upwelling and downward control}

The meridional residual circulation $\left(\bar{v}^{*}, \bar{\omega}^{*}\right)$ as introduced in the transformed Eulerian mean (TEM) equations (e.g. Holton, 2004) is used here for quantifying the largescale circulation in the stratosphere. As a measure of the strength of the upwelling branch of the circulation, mean tropical upwelling is calculated by integrating over all lat-

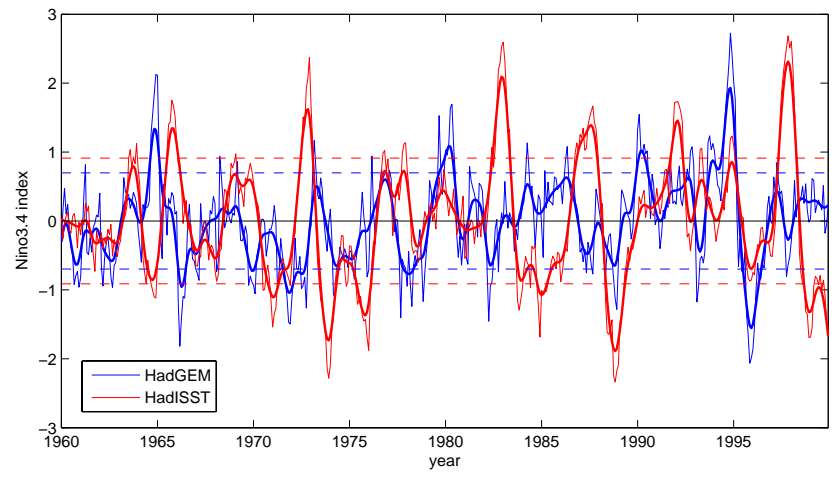

Fig. 3. Timeseries of the nino3.4 index from HadISST (red lines) and HadGEM (blue lines). The heavy lines are running averages of the monthly timeseries, and dashed lines show the standard deviation $( \pm 1 \sigma)$.

itudes within $60^{\circ} \mathrm{N} / \mathrm{S}$ where the residual vertical velocity points upward (i.e. negative $\bar{\omega}^{*}$ since $\omega=\frac{\partial p}{\partial t}$ ):

$U_{\text {tropics }}=\int_{\phi_{\bar{\omega}^{*}<0}} \frac{2 \pi \cos (\phi) r_{e}^{2}}{g} \bar{\omega}^{*} d \phi$

In addition to this direct calculation from the residual vertical velocity, tropical upwelling was calculated using the downward control (DC) principle (Haynes et al., 1991). The DC principle states that the residual circulation at a certain level is driven by the forcing on the mean flow above this level. By using the EP divergence as forcing, the contribution of planetary wave activity in driving the BDC can be quantified.

The DC calculations were performed as follows. From the continuity equation for $\left(\bar{v}^{*}, \bar{\omega}^{*}\right)$, the residual streamfunction $\overline{\chi^{*}}$ can be introduced:

$\left(\bar{v}^{*}, \bar{\omega}^{*}\right)=\frac{1}{\cos (\phi)}\left(-\frac{\partial \overline{\chi^{*}}}{\partial p}, \frac{1}{r_{e}} \frac{\partial \overline{\chi^{*}}}{\partial \phi}\right)$

Using the TEM momentum equation and assuming a nonzero meridional gradient of the zonal mean angular momentum $\bar{m}=r_{e} \cos (\phi)\left(\bar{u}+r_{e} \Omega \cos (\phi)\right)$ and stationary conditions, the residual streamfuncion $\overline{\chi^{*}}$ can be expressed as (for details see Haynes et al., 1991):

$\bar{\chi}^{*} \bar{m}_{0}(p)=\int_{p}^{0}\left[\frac{r_{e}^{2} \cos (\phi)^{2} G}{\partial \bar{m} / \partial \phi}\right]_{\phi=\phi\left(\bar{m}_{0}\right)} d p^{\prime}$

Here $G$ is assumed to be the EP divergence (appropriately rescaled to units of $\left.\mathrm{m} / \mathrm{s}^{2}\right)$, and the subscript $\phi=\phi\left(\bar{m}_{0}\right)$ denotes integration along lines of constant angular momentum. The condition $d \bar{m} / d \phi \neq 0$ limits the latitude region of the calculation to outside the inner tropics. In practice, the integration along constant angular momentum can only be performed when $\bar{m}_{0}$ is a real function of pressure, i.e. the $\bar{m}_{0}$ contour is not closed in the domain of calculation. 
For estimating tropical upwelling as given in Eq. (2), it is used that $\overline{\omega^{*}}=1 /\left(r_{e} \cos \phi\right) \overline{\chi^{*}}{ }_{\phi}$ so that upwelling between latitudes $\phi_{1}$ and $\phi_{2}$ is given by $2 \pi r_{e} / g\left[\overline{\chi^{*}}\left(\phi_{2}\right)-\overline{\chi^{*}}\left(\phi_{1}\right)\right]$ (Randel et al., 2002). In order to capture the same latitude band as for the direct tropical upwelling calculation (Eq. 2), the turnaround latitudes (where $\bar{\omega}^{*}$ changes sign) are deduced from the residual vertical velocity for each month and the streamfunction is then calculated at these latitudes. In a few cases, the turnaround latitudes were too deep in the tropics, so that the integration along $\bar{m}_{0}$ was not possible. In these cases, tropical upwelling was set to zero. The mean location of the turnaround latitudes did not differ between the REF1 and the SCN2 simulation in a statistical significant way. Also, trend analyses of the turnaround latitudes showed that there are no significant changes in the location and the width of the upwelling region in both simulations. Therefore changes in total upwelling can not be attributed to changes in the width of the upwelling region. However, due to the relatively coarse horizontal resolution of the model (T30), changes of the width of the tropical belt in the order of one to two degrees per decade, as reported by Seidel and Randel (2007), might not be detectable here.

\section{Climatological differences}

\subsection{Temperature and ozone}

To address the question to which extent CCM simulations using observed and modelled SSTs, respectively, differ in their climatological mean state, the 40-year climatologies (19601999) of temperature and ozone mixing ratios are compared (Fig. 4).

The tropospheric temperatures in the $\mathrm{SCN} 2$ simulation are significantly lower than in REF1, with differences maximising in the tropical middle troposphere. There the temperature is up to $1.5 \mathrm{~K}$ lower in SCN2. In the stratosphere, the temperature differences are generally weaker but temperatures are significantly higher in SCN2 in the tropical lower stratosphere and at high latitudes at around $200 \mathrm{hPa}$. The temperature differences in the troposphere between the two simulations are of the same order of magnitude as changes over the 40 years of each model simulation (see Fig. 7). The large differences in the climatologies are not unexpected since differences between the SST climatologies of the two runs are more than $1 \mathrm{~K}$ in the zonal mean for most latitudes (see Fig. 1), and even up to $3 \mathrm{~K}$ at about $50^{\circ} \mathrm{N}$. The difference pattern in temperature is in close agreement with results from earlier studies on SST forcing of temperature (see e.g. Kodama et al., 2007; Hardiman et al., 2007).

The differences in the ozone climatology show significantly higher ozone mixing ratios in the tropical lower stratosphere and lower ozone mixing ratios at southern middle and northern high latitudes in SCN2 compared to REF1. Additionally, there are significant differences in the troposphere with higher ozone mixing ratios in the tropics and at high latitudes. The difference pattern in ozone mixing ratio in the stratosphere is clearly indicative of weaker transport from the tropics into higher latitudes in SCN2. To examine the differences more closely, Fig. 5 (left panel) shows the annual cycle of zonal mean total column ozone for all latitudes (from REF1, 1960-1999) and differences between SCN2 and REF1. The negative ozone differences are strongest in northern winter at high latitudes (maximising in February) and in southern mid-latitudes in May to October, occurring in both hemispheres one to two months before total ozone maximises.

\subsection{Residual circulation}

The distribution of total column ozone is determined by both chemical and dynamical processes. While the photochemical production of ozone is highest in the tropics, the BDC is transporting ozone from the tropics towards higher latitudes.

The classical view is that transport by the dominant winter cell of the BDC leads to the ozone maximum in middle to high latitudes of the winter/spring hemisphere. However, next to the direct transport of ozone by the BDC, also other mechanism might play a role, like eddy mixing of tropical air masses into mid-latitudes or the local ozone chemistry. Grewe (2006) showed that in the mid-latitudes the contribution of ozone originating in the tropics is about half of the total amount of ozone, with the other half being produced locally. Detailed analyses of the processes important to the redistribution of ozone, and in particular the relation of changes in theses processes to changes in ozone concentrations are not scope of this study and are subject of ongoing work. However, it has been shown in various studies (Fusco and Salby, 1999; Randel et al., 2002) that ozone anomalies can be linked to variations in wave fluxes, which drive the BDC. Also, Jiang et al. (2007) showed recently that changes of the BDC can be related to changes in the amount of ozone with reduced ozone concentrations in the tropics and enhanced ozone concentrations in mid-latitudes.

Figure 5 shows next to the ozone climatology of REF1 (left) the climatology of the streamfunction of the residual velocity $\overline{\chi^{*}}$ at $100 \mathrm{hPa}$, as measure of the $\mathrm{BDC}$ (right). The $100 \mathrm{hPa}$ level is chosen since the differences in the ozone climatologies are largest in this height region (see Fig. 4). The streamfunction clearly shows the dominant winter circulation cells, with a maximum of the Northern Hemisphere circulation in January and of the Southern Hemisphere circulation in June. Total column ozone maximises poleward and about 1-2 month after the circulation maxima.

The difference pattern in the residual circulation clearly shows a weaker circulation in SCN2 in both hemispheres during autumn and early winter in low latitudes. In the Northern Hemisphere, weaker transport sets in around August and total ozone values start to be significantly lower around October. The weaker meridional circulation persists 

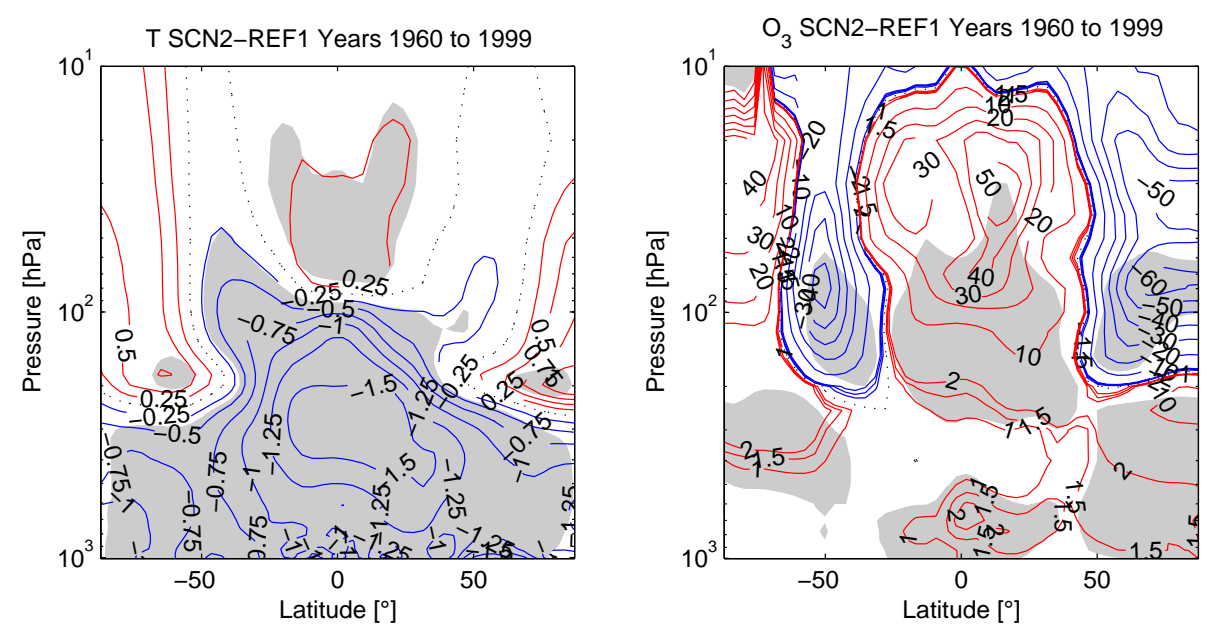

Fig. 4. Difference of 1960 to 1999 temperature [in K] (left) and ozone mixing ratio [in ppbv] (right) climatologies in REF1 and SCN2. Shown are differences SCN2 minus REF1, grey shading indicates statistic significance of the differences (on the 95\% level).
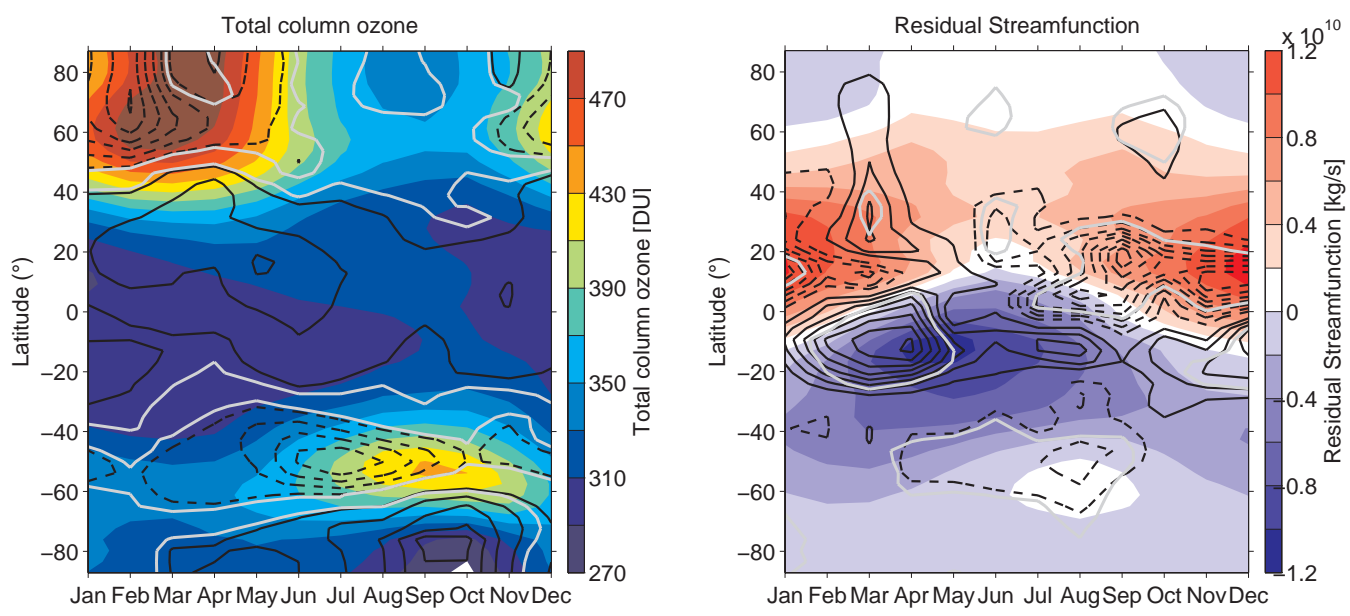

Fig. 5. Total column ozone (left) and residual streamfunction ( $\chi^{*}$, see Eq. 3) at $100 \mathrm{hPa}$ (right) 40 -year climatologies (coloured) of REF1. Differences SCN2-REF1 are shown as black solid contours (for positive values) and dashed contours (for negative values). The contour interval is $2 \mathrm{DU}$ for total column ozone and $2 \times 10^{9} \mathrm{~kg} / \mathrm{s}$ for the residual streamfuntion. Within light grey contours, differences are statistical significant on the $95 \%$ level.

throughout autumn until January, and consequently total ozone does not build up at mid to high latitudes as strongly in SCN2 as in REF1. In February to March meridional transport becomes stronger in $\mathrm{SCN} 2$, leading to the weak positive difference in total ozone in April at high latitudes.

In the Southern Hemisphere a similar picture emerges, with a weaker circulation in SCN2 leading to lower ozone values. Here, the meridional circulation in the (sub-)tropics is weaker throughout the year, but differences are largest in February to May. The weaker transport again leads to lower ozone values in mid-latitudes, lagging about 2 month after the maximal circulation difference.

\subsection{Planetary wave activity}

Since the large-scale circulation in the stratosphere is largely driven by planetary waves, the differences in the meridional circulation as found in the last section are expected to result from differences in wave activity. The climatology of EP fluxes of the REF1 simulation was shown in Stenke et al. (2009), and showed a generally realistic representation of planetary wave (PW) activity in the model. Annual mean differences between SCN2 and REF1 in EP divergences and fluxes are shown in Fig. 6. It can be seen that there is less wave activity entering the stratosphere in the tropics, resulting in less wave dissipation and therefore a weaker forcing of the BDC in the SCN2 simulation. This results in weaker upwelling around the equator, balanced by weaker downwelling 
around $20^{\circ} \mathrm{N} / \mathrm{S}$. At high latitudes there are indications of a stronger circulation in SCN2 in both hemispheres.

The difference pattern of EP fluxes in the stratosphere suggests that even though there is a strong positive anomaly in wave generation equatorward of $50^{\circ} \mathrm{N} / \mathrm{S}$, stronger dissipation between $400 \mathrm{hPa}$ and $100 \mathrm{hPa}$ lead to less wave activity reaching the stratosphere. Also, especially in the Northern Hemisphere there are signs of stronger poleward refraction of PWs. However, statements about the cause and effect relationship of wave-mean flow interactions that lead to the observed differences in the residual circulation are not easily deduced from the data. The discussed differences in EP fluxes are largely statistically significant, even more so when considering stationary waves only (not shown).

\section{Long-term trends and variability}

While in the last section, the climatological differences due to different SST data sets were studied, the following part of the paper aims to analyse differences in the temporal evolution.

\subsection{Temperature and ozone}

The linear trend in annual mean zonal mean temperature and ozone mixing ratios over the years 1960 to 1999 was calculated for each latitude and pressure level, and the resulting trend patterns are shown in Fig. 7. The results show that the trend patterns calculated for REF1 and SCN2 are similar both in terms of geographical locations and magnitudes of trend maxima and minima for temperature as well as for ozone.

In terms of temperature, both simulations show a warming of approximately $1 \mathrm{~K}$ over 40 years in the troposphere and a cooling pattern in the stratosphere with strongest cooling of up to $4.5 \mathrm{~K}$ near the south pole and a local cooling maximum in the tropics. The temperature trends are significantly different (on the 95\% level) only in the Northern Hemisphere mid-latitudes in the troposphere, consistent with weaker SST trends in the mean over the Northern Hemisphere of the HadISST data than of HadGEM1 (see Fig. 2).

The ozone trend pattern shows a strong decrease of ozone mixing ratios in the stratosphere, especially in high southern latitudes and an increase in the troposphere. The differences between the two simulations in the 40-year zonal mean ozone trends are not statistically significant for all latitudes and levels.

To study the temporal evolution of temperature and ozone more closely, time series of total column ozone and $30 \mathrm{hPa}$ temperatures (as representative for the lower stratosphere) for certain latitude bands are shown in Figs. 8 and 9. Only winter/spring months are shown since the stratospheric variability is highest in this time of the year. Also, SSTs are expected to influence the stratosphere mainly through dif-

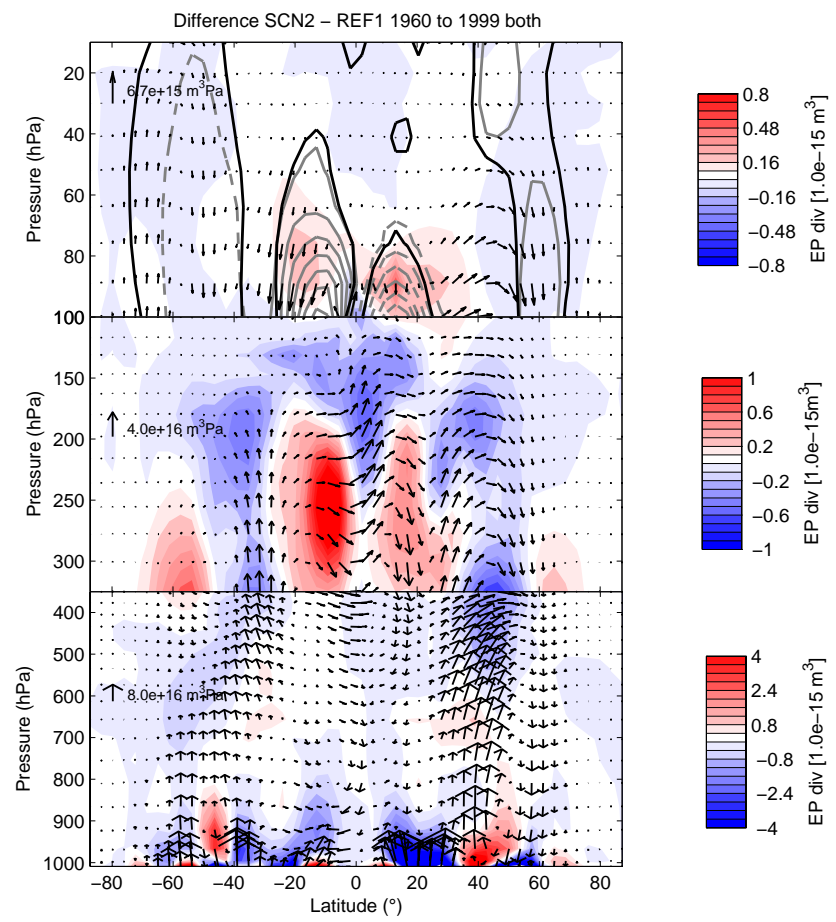

Fig. 6. Differences (SCN2-REF1) of 40-year climatologies of annual mean EP fluxes (black arrows) and EP divergences (coloured) for three different height regions. The scaling of the EP fluxes and divergences is indicated by the scale arrow and the colorbar in each panel. Light grey contours in the upper panel show differences (SCN2-REF1) in the residual meridional circulation, with solid lines denoting positive values and dashed lines denoting negative values (contour interval is $5 \times 10^{7} \mathrm{~kg} / \mathrm{s}$ ). Differences in the residual circulation are statistically significant within black contours.

ferences in planetary wave activity, which is communicated to the stratosphere mainly in winter when wave propagation is not inhibited by easterly winds (Randel and Held, 1991; Charney and Drazin, 1961).

Much of the interannual variability in ozone can be explained by external forcings like the QBO and the solar cycle (e.g. Steinbrecht et al., 2006). The co-variability of the time series of the two simulations, as measured by the correlation coefficient, gives a measure of how deterministic the system is, i.e. how strong the common external forcings (like the QBO or the solar cycle) act to determine the anomalies in individual years. Low correlation coefficients can be caused by either internal variability or by forcing that is different in the two simulations, i.e. the SSTs. The ENSO is excepted to cause anomalies in ozone and temperature by modifying planetary wave activity and its impact will be discussed in Sect. 5.3. The correlation of the detrended time series of total column ozone (left panels of Fig. 8) is significant for the tropics and for the Southern Hemisphere (with correlation coefficients of approximately 0.5 ), while in the Northern Hemisphere the high dynamic variability causes the correlation to 

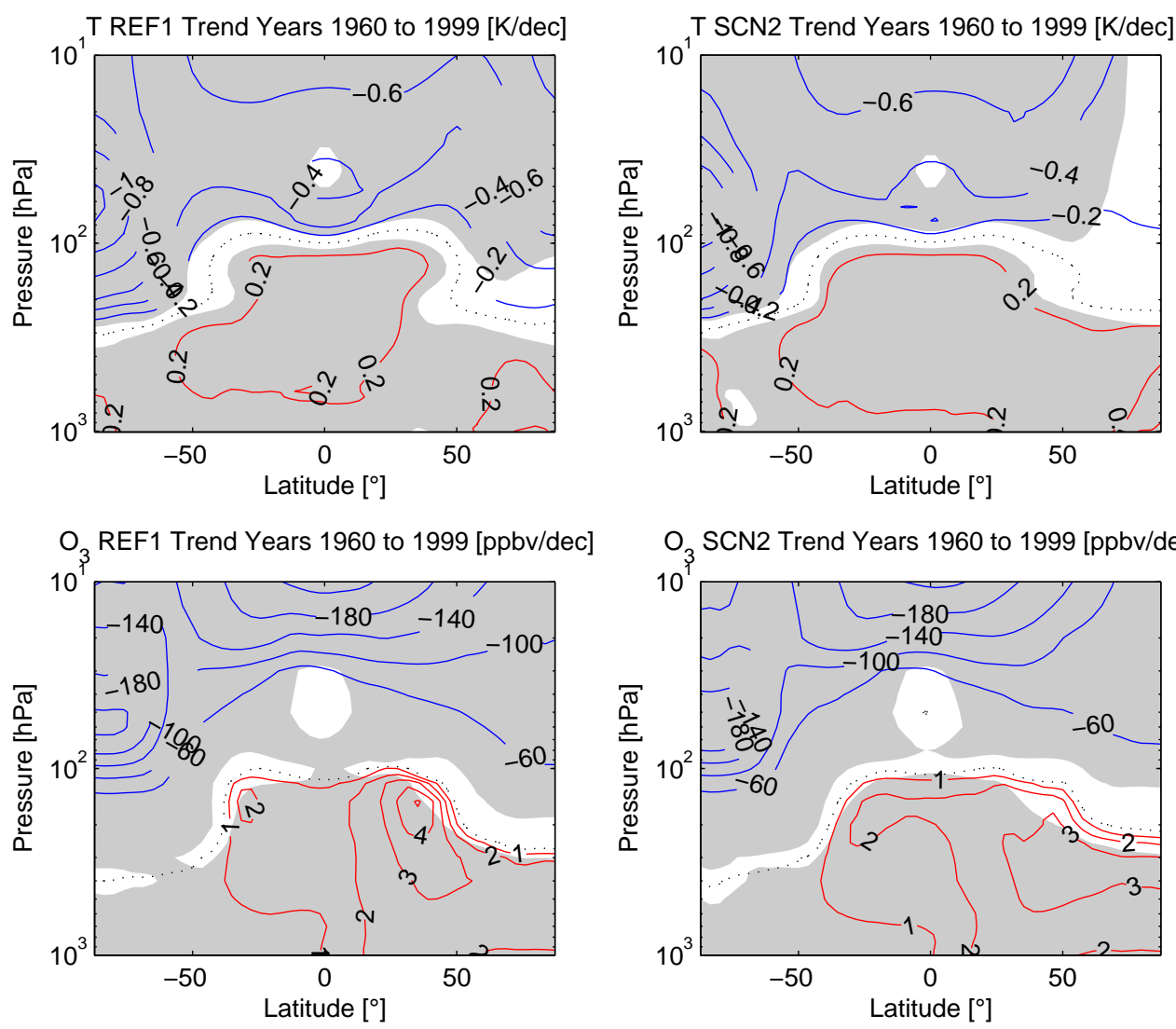

Fig. 7. Linear trends over years 1960 to 1999 of temperature (upper panels) and ozone mixing ratio (lower panels) for REF1 (left) and SCN2 (right). Units are K/decade and ppbv/decade, respectively. Grey shading indicates statistic significance of the trends (on the $95 \%$ level).

be insignificant. Since both model runs are driven by the same boundary conditions (apart from the SSTs), anomalies that are driven by e.g. the QBO or the solar cycle should be apparent in both simulations. For example, the very low total column ozone value over southern mid-latitudes in 1985 is reproduced by both model runs. The negative anomaly was a combined effect of the QBO, the solar cycle and their timing in the year (Bodeker et al., 2007).

The detrended temperature time series of the SCN2 and REF1 runs as shown in Fig. 9 correlate significantly in the tropics and in the mid-latitudes of both hemispheres. The correlation coefficients are $0.58,0.47$ and 0.35 in the northern mid-latitudes, the tropics and the southern mid-latitudes, respectively. Especially in the tropics, the variability seems to be largely dominated by the QBO, which is apparent particularly in the last decade of the time series.

The essential question when comparing the REF1 and $\mathrm{SCN} 2$ simulations is on the reproduction of the temporal evolution of the atmosphere. Above, it was shown that the 40year trend pattern in ozone and temperature are not significantly different from each other. But is this still true when the length of the time series is shortened? To answer this question, the linear trend in total column ozone and temperature was calculated for periods of increasing length, starting with 1960 to 1974 and extending the period in steps of one year until 1999 (see right panels of Figs. 8 and 9). If the trend would be strictly linear, it would be constant for all periods. Otherwise, if for example total ozone was increasing during the first 20 years and decreasing with the same rate during the second half of the total period, the trend would be positive during the first 20 years, then decrease and equal out to zero at the end.

The results for total column ozone (Fig. 8) show good agreement in trends calculated from the two simulations in southern high latitudes, where the strongest negative trend appears due to rapid ozone depletion. The trend increases for longer periods since the rapid ozone depletion only started in the 1980s, so that the trend is close to zero for a short period and increases afterwards. In the mid-latitudes and tropics, the absolute values of the ozone trends are very similar when including more than about 25 years of model simulation. In the tropics, the trend estimated for a period spanning from 1960 to around 1980 is positive in the REF1 run but close to zero or negative for the SCN2 run. In turn, the trends at middle and high northern latitudes in the same period are strongly negative in REF1 in the late 1970s, but close to zero 


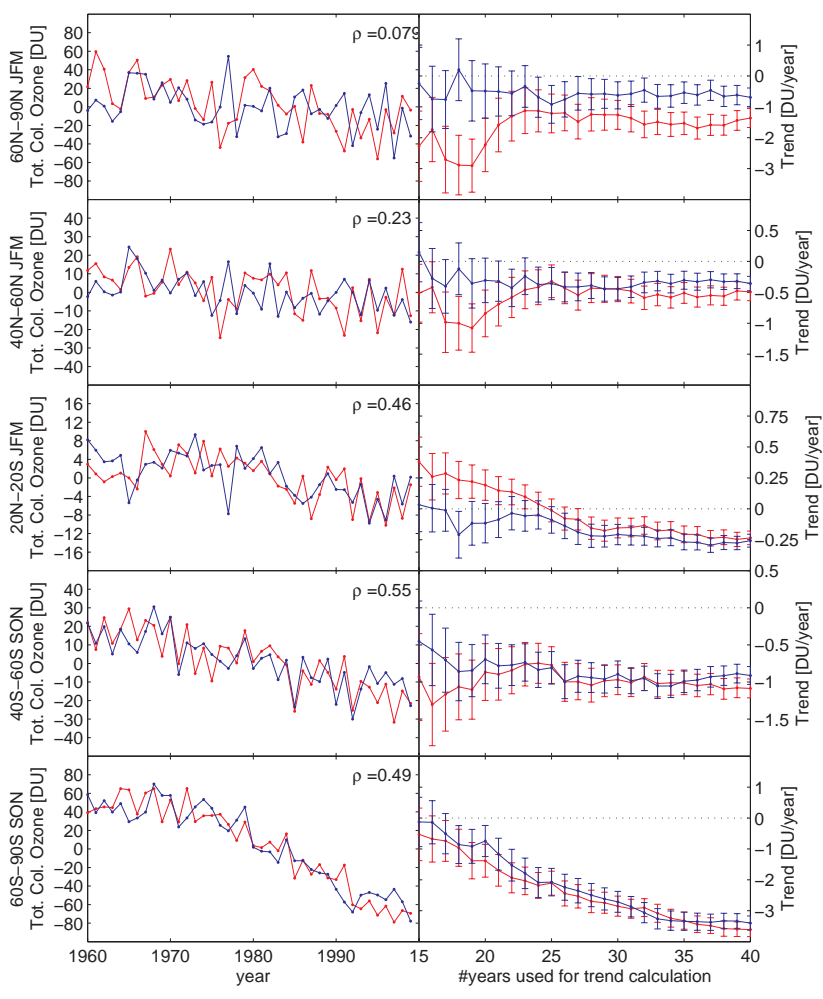

Fig. 8. Mean total column ozone anomalies in [DU] for various latitude bands for REF1 (red) and SCN2 (blue). The number in the upper right corner is the correlation coefficient between the two time series. Right panels show linear trends as a function of the number of years after 1960 used for the trend calculation. The error bars on the trend coeffients are their uncertainties ( $\sigma$, see Sect. 3).

in SCN2. This leads to the trend calculated over the whole period being weaker in REF1 as in SCN2.

The trend calculations in the same manner for the temperature time series give similar results (see Fig. 9 right panels). The linear trend calculated over time periods including more than 25 years agree well between the model runs. Trends over shorter periods differ in magnitude at northern high latitudes. As for ozone, the trends in northern high latitudes are strongly negative for periods 1960 to around 1979 for REF1 and close to zero for SCN2. The behaviour is reversed in the tropics (with positive trends in REF1 and small (negative) trends in SCN2), but the differences in trends are not significant here.

This difference in trends during the period 1960 to the late 1970s in both total column ozone and temperature might either be (i) of non-deterministic nature, caused by internal model variability or (ii) forced externally and therefore due to differences in the forcings of the two simulations. If it was a process forced by an external boundary condition, the only possible boundary condition to cause this modulation in trends are the prescribed SSTs, since this is the only difference in the external forcing of the REF1 and SCN2 sim-

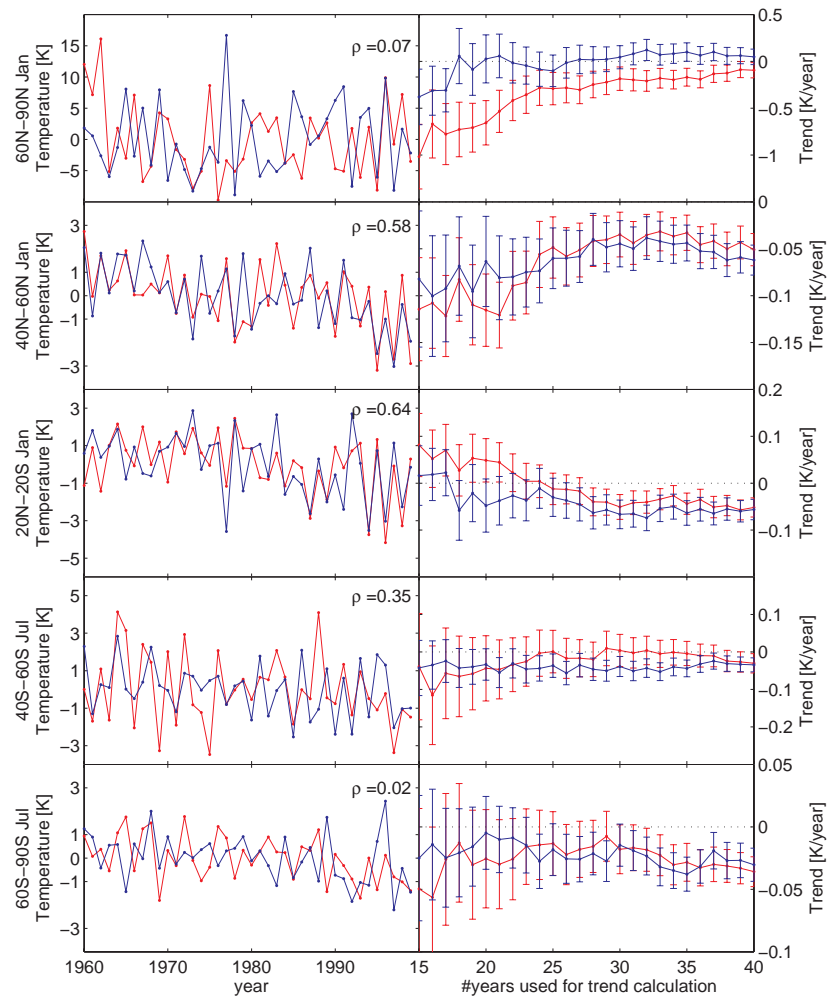

Fig. 9. As in Fig. 8 but for temperature in $[\mathrm{K}]$ at $30 \mathrm{hPa}$.

ulations. As shown in Fig. 2, the time series of SSTs differ in particular in the Northern Hemisphere in the 1960/1970s. Therefore, we suspect that changes of SSTs alter the temporal evolution of stratospheric ozone and temperature in a way similar to the climatological differences found in Sect. 4. The mechanism of how SSTs are expected to act on stratospheric temperature and ozone distributions are dynamical processes, i.e. the modulation of PW activity. Indeed, the fact that positive trends in the 1960/1970s (in both temperature and ozone) in the tropics seem to be balanced by strong negative trends in middle and high latitudes in the winter hemisphere suggest that the underlying mechanism is related to changes in the large-scale circulation (which is in turn driven by PW activity). In order to investigate the hypothesis of SST-induced dynamical changes, the temporal evolution of the BDC and PW activity for the two simulations with different underlying SSTs will be investigated in the next section.

\subsection{Brewer-Dobson circulation and planetary wave activity}

To quantify changes in the large-scale circulation of the stratosphere, time series of mean tropical upwelling for December to February (DJF) are shown in Fig. 10 for REF1 and SCN2. Significant changes in tropical upwelling with time were found only for DJF, so that in the following only 

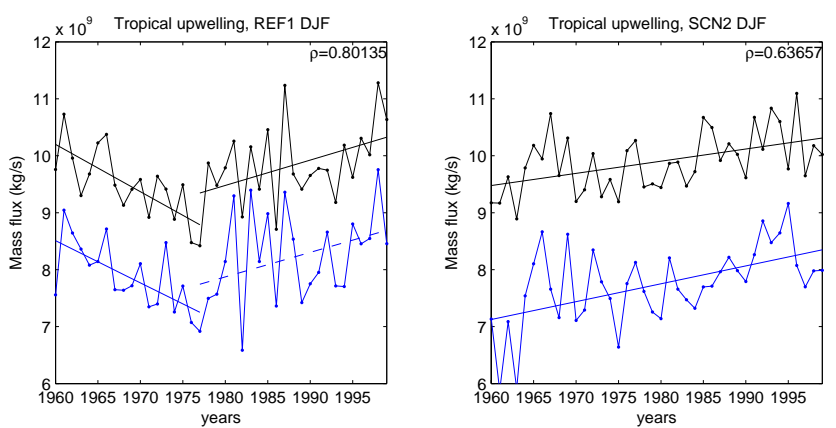

Fig. 10. Mean tropical upwelling (as measured by mass fluxes) at $76 \mathrm{hPa}$ for December to February for REF1 (left) and SCN2 (right). Shown is tropical upwelling derived directly from the residual velocity (black lines) and upwelling calculated using downward control (blue lines). Together with the time series, linear trends are shown (as solid line for significant trends, otherwise dashed). In the upper right corner, the correlation coefficient between the time series of tropical upwelling calculated directly and via DC is given.

northern winter months are considered. As Fig. 10 shows, the temporal evolution of tropical upwelling is fairly different in the two simulations. While in SCN2, tropical upwelling increases throughout the period 1960 to 1999, in REF1 a clear reverse in the trend is seen in the late 1970s. As mentioned above, the temperature and ozone time series are indicative of a weakening of the BDC in the REF1 simulation during the 1960s and 1970s, and the tropical upwelling time series strongly supports this suggestion. As discussed above, the fact that the reverse in trends only occurs in the simulation with observed SSTs strongly suggests that differences in the temporal evolution of the SSTs drive these changes in the large-scale circulation. However, the most likely mechanism for SSTs affecting the BDC is via changes in planetary wave generation or propagation as the main drivers of the BDC. Therefore, in the following the contribution of planetary wave activity in forcing upwelling and changes in the wave activity are analysed.

The contribution of planetary wave activity to forcing changes in upwelling can be quantified by calculating tropical upwelling via the downward control principle (see Sect. 3). Using this method, the trends in upwelling can be reproduced, especially the strong negative trend in DJF in the first 20 years in REF1. This shows that the changes in the BDC can be linked to changes in the dissipation of planetary wave activity in the stratosphere. PWs are largely generated in the troposphere, propagate upward and dissipate due to respective background conditions (see e.g. Charney and Drazin, 1961). Therefore, changes in wave activity divergence can be caused by either changes in the generation, the propagation and/or the region of dissipation of waves.

Figure 11 shows the linear trend in EP fluxes and divergence and in the streamfunction of the residual circulation for the REF1 simulation over the period 1960 to 1978 in January, where tropical upwelling decreases. For SCN2, trends over the period 1960 to 1999 , where tropical upwelling increases, are shown. For REF1, the period 1978 to 1999 also shows an increase in tropical upwelling and the trend pattern in the residual circulation and EP fluxes are qualitatively similar to the SCN2 1960-1999 period, even though the shorter time period makes it more difficult to obtain significant trends.

The REF1 1960-1978 trend pattern of the residual velocity shows a strong significant hemisphere-wide decrease in the circulation strength of the Northern Hemisphere (Fig. 11 left panel). This weakening in the residual circulation is clearly linked to a negative trend in EP divergence in the extratropical stratosphere above $60 \mathrm{hPa}$. The trend in $\mathrm{EP}$ fluxes suggests that the origin of the EP divergence change lies in the tropospheric production of wave activity. The decrease in tropospheric wave generation is found in northern midlatitudes, in particular between $35^{\circ} \mathrm{N}$ and $60^{\circ} \mathrm{N}$.

For the period 1960 to 1999 in SCN2 a clear increase in the residual streamfunction and therefore in the strength of the BDC is seen in both hemispheres (Fig. 11 right panel). The trends in the residual streamfunction are significant in the (sub-)tropics below $80 \mathrm{hPa}$, with rising motion around the equator and downwelling equatorward of about $20^{\circ} \mathrm{N} / \mathrm{S}$. Also in the Southern Hemisphere at middle and high latitudes, the trend towards a stronger BDC is significant. The (sub-)tropical circulation changes can be associated with increases in EP convergence in the same region.

In the mid-latitudes, both hemispheres show enhanced EP flux entering the stratosphere and therefore enhanced EP convergence at higher levels, but the changes are statistically significant only in the Southern Hemisphere. The changes in EP flux entering into the stratosphere in southern midlatitudes can not be attributed to stronger wave generation but the trend pattern indicates reduced dissipation in the upper troposphere.

\subsection{Influence of ENSO on tropical upwelling}

As pointed out in the introduction, the ENSO has been shown to modulate planetary wave activity and the meridional circulation in earlier studies. Since the SSTs, and therefore ENSO, are the only external forcing that differs in the two simulations examined here, it might be a cause for the differences found in the temporal evolution of tropical upwelling. The signal of the ENSO forcing can also be expected to be found in temperature and ozone (i.e. Figs. 8 and 9), but since these signals are driven by changes in tropical upwelling, we focus on analysing the impact of ENSO on the latter.

To this end, correlation coefficients between tropical upwelling and the ENSO time series over 40 years are calculated and given in Table 1 for both model simulations used in this study. The correlations are not significant for JJA and in the annual mean for both model runs, but in DJF the correlation is significant on the 95\% level in REF1. The stronger correlation in DJF in REF1 compared to SCN2 is reflective of the weaker ENSO signal, and therefore weaker forcing, in 

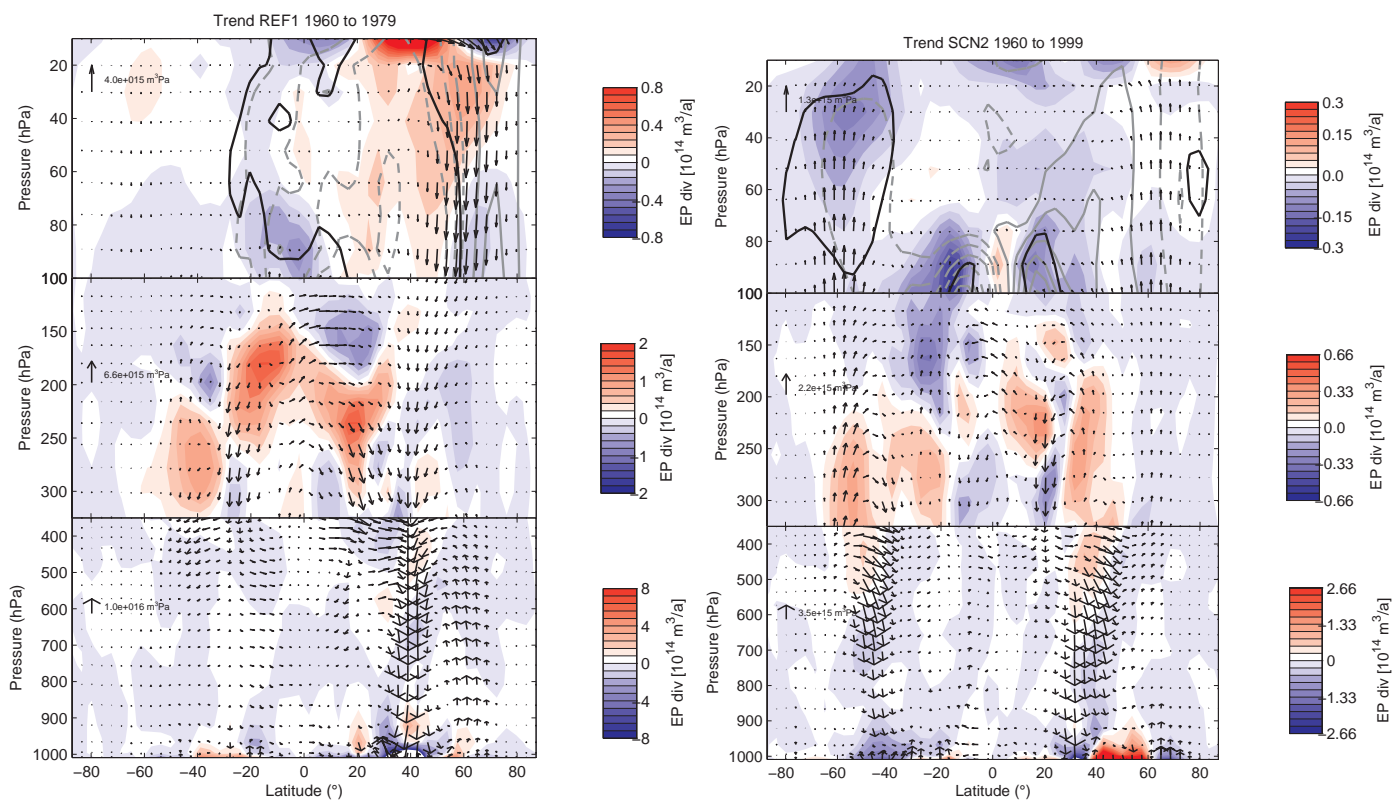

Fig. 11. As in Fig. 6, but showing the linear trend in EP fluxes and divergence and in the residual circulation for REF1, years 1960 to 1979 (left panels) and SCN2, years 1960 to 1999 (right panels). Contour intervals for the residual streamfunction is $2.5 \times 10^{7} \mathrm{~kg} / \mathrm{s} / \mathrm{a}$ in the left panel and $0.7 \times 10^{7} \mathrm{~kg} / \mathrm{s} / \mathrm{a}$ in the right panel.

the HadGEM SST data set (see Fig. 3). The positive correlation between ENSO and tropical upwelling is in agreement with the studies by García-Herrera et al. (2006) and Hardiman et al. (2007), that state stronger wave activity and subsequent forcing of the BDC in positive phases of the ENSO.

To investigate how much of the variability in tropical upwelling can be attributed to ENSO, a linear least square regression model with the ENSO as basis function was applied to the monthly tropical upwelling time series. Seasonal variations in the regression coefficients is accounted for by introducing a Fourier expansion of the coefficients (see Garny et al., 2007 for details). Due to possible delays in the response of tropical upwelling on ENSO, up to 11 month time lag was allowed, but it proved that the optimal fitting (measured as the smallest sum of squared residuals) is given for the instantaneous ENSO values (i.e. a time lag of 0 month). Due to the weak correlation in SCN2, this analysis is shown here only for REF1 where an influence of ENSO on tropical upwelling is evident from the significant correlation.

Figure 12 shows the DJF mean time series of tropical upwelling as in Fig. 10 together with the time series as modelled by the regression, i.e. the variability in tropical upwelling that can be explained by a linear relationship to ENSO. This suggests that although the ENSO is responsible for some variability in tropical upwelling, the trends either in in 1960/1970s or afterwards can not be attributed solely to ENSO. However, this analysis assumes a linear relationship between tropical upwelling and ENSO, so nonlinear effects might amplify the response of ENSO in certain conditions, which could change the conclusion of this section.
Table 1. Correlation coefficients between tropical upwelling and ENSO for REF1 and SCN2 in seasons DJF, JJA and for annual mean values.

\begin{tabular}{lrr}
\hline Season & REF1 & SCN2 \\
\hline DJF & 0.32 & -0.03 \\
JJA & -0.20 & -0.17 \\
annual & -0.09 & 0.02
\end{tabular}

\section{Summary and conclusions}

The comparison of two transient E39C-A simulations using observed and modelled SSTs, respectively, showed that there exist large differences in temperature and ozone climatologies. The differences in ozone are linked to small, but statistically significant differences in the residual meridional circulation, which are in turn driven by differences in PW activity fluxes. Detailed trend analyses showed generally good agreement in long-term trend pattern of zonal mean temperature and ozone mixing ratios. However, differences in trends were found when considering shorter time series.

In the comparison of the two simulations that are identical except for the SST (including sea ice coverage) data sets, it is straightforward to attribute the climatological differences to SST differences. The differences in the temporal evolution in the two simulations, on the other hand, could simply be due to internal variability of the system. Therefore, the only conclusion that can be drawn for sure is that in cases where we find differences in the trends, the trend in the particular 


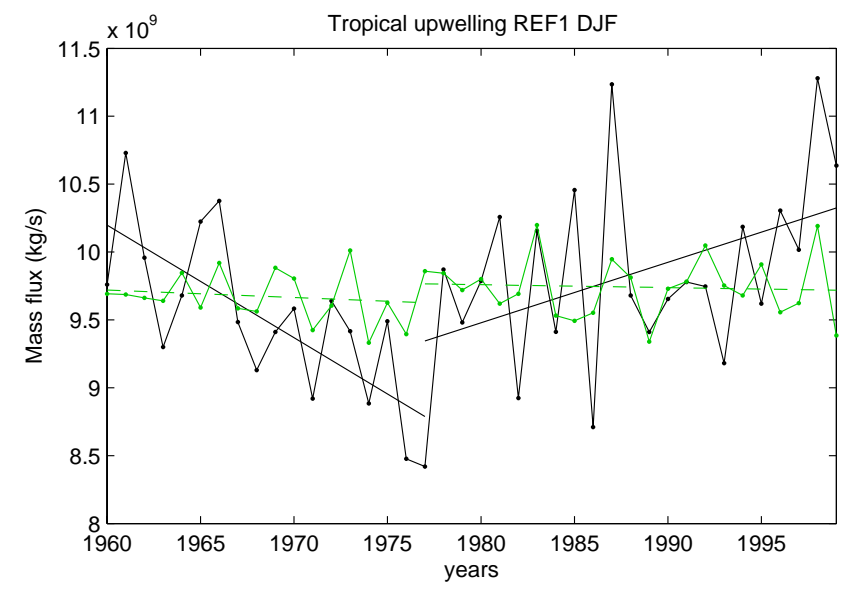

Fig. 12. Mean tropical upwelling (as measured by mass fluxes) at $76 \mathrm{hPa}$ for December to February for REF1. The black line shows the full time series of tropical upwelling, the green line the variability in tropical upwelling that can be explained by ENSO (see text for more details). Together with the time series, linear trends are plotted as solid lines when statistically significant (on the $95 \%$ level), otherwise as dashed lines.

quantity is not robust. Whether this is due to the internal variability or due to the use of different SST data sets can not be concluded on. It would be desirable to have more than one realisation of each simulation to test whether the behaviour is deterministic.

For the inter-simulation comparison, the results suggest enhancement or reduction in planetary wave generation and subsequently changes in the large-scale circulation in the stratosphere as the mechanism of how SST signals are communicated to the stratosphere. This can be seen in differences of ozone climatologies between the two runs, which show clear signals of changes in transport of ozone from the tropics to higher latitudes. Also the temperature climatology comparison shows significantly higher temperatures in the tropical lower stratosphere, an indication of weaker rising of air masses in this region. The difference pattern in the residual circulation confirms that the BDC is weakened, as a result of less PW flux propagating into the stratosphere.

As it was mentioned in the introduction, most climate and chemistry-climate models show an increase of the BDC in a changing climate. The findings of the study presented here agree in that an increase of tropical upwelling with time in the SCN2 simulation and in REF1 after 1980 is diagnosed. The trend pattern of the residual streamfunction in the simulations suggest that the changes consist of a strongly enhanced circulation constrained to the (sub-)tropics and of significant changes in the Southern Hemisphere. The changes in the Southern Hemisphere are forced by stronger extratropical planetary wave flux into the stratosphere, which in turn seems to be caused by changes in wave propagation. The changes in wave activity in southern summer are most likely a result of changes in the dynamics due to ozone loss. For example, Li et al. (2008) suggested a mechanism of increased descent in the Antarctic vortex leading to a stronger meridional temperature gradient and therefore a stronger jet which in turn leads to enhanced upward planetary wave propagation. The fact that trends in the Southern Hemisphere are absent in the period 1960 to 1978 confirms this hypothesis. The changes in the tropics are linked to changes in PW activity within the tropics, with enhanced EP fluxes entering the stratosphere at $100 \mathrm{hPa}$ and subsequently enhanced EP convergence in the tropical lower stratosphere. The pattern in the trend of the residual circulation is similar to the differences diagnosed between SCN2 and REF1. Also Deckert and Dameris (2008a) reported changes in the circulation in the tropics, and attributed the changes to enhanced wavedriving by changes in convective activity due to higher SSTs (see also Introduction). The changes in EP fluxes and the residual circulation seem to be a robust pattern, and the difference and trend patterns found in this study are probably of the same nature as the changes reported on in Deckert and Dameris (2008a). As discussed above, the differences between the two simulations can be attributed to differences in SST forcing, being consistent with the hypothesis of Deckert and Dameris (2008a). The positive trend in the BDC as found in SCN2 and in REF1 after 1980, on the other hand, can not be concluded on being driven by SSTs from the current findings presented here. Other processes could be responsible, like changes in the mean zonal winds due to changed GHG concentrations that lead to increased extratropical PW activity. However, the fact that the difference in the residual circulation between the simulations appears similar to the trend pattern provides an indication that the SSTs, and therefore changes in tropospheric processes, might be the controlling factor in driving the trends in the BDC. However, to untangle the exact cause and effect relationships of the processes responsible more detailed studies with various different model systems will be necessary.

The 1960-1979 negative trends in upwelling in REF1 were shown to originate from EP flux trends indicative of less PW generation in the extratropical troposphere. The period of decreases in EP fluxes in the troposphere coincides with a decrease in Northern Hemisphere mean SSTs over the same period (see Fig. 2). This suggests some evidence that the trend in upwelling is indeed forced by the SSTs and not an artefact of this particular realisation. However, one major problem of trying to attribute the changes to SST trends is the lack of understanding of how extratropical SST anomalies can affect the excitation of planetary waves (Kushnir et al., 2002). Peng et al. (1995) and Peng and Whitaker (1999) showed that the response to SST anomalies is highly sensitive to the background state, i.e. the response to the same anomaly might be of different nature for different month, but also appears different when using different models.

Unlike for the extratropics, the effects of tropical SST anomalies and namely the ENSO on extratropical waves 
(Ineson and Scaife, 2009), and subsequently modulation of the PW flux into the stratosphere and the BDC (Hardiman et al., 2007; García-Herrera et al., 2006) are well studied. It is shown that this relationship also holds for the REF1 simulation used here, with positive correlations of tropical upwelling with the ENSO index in the northern winter season. In the mid-1970s, two strong negative ENSO events occurred, indicative of weakened wave activity. This may appear as a possible explanation of the weak BDC in the 1970s in REF1, but it could not be confirmed that ENSO alone is responsible for the negative trend in tropical upwelling in the $1960 / 1970$ s by a regression analysis. Since this analysis only takes the linear response of upwelling on ENSO into account, it might not capture the full response, and more studies will be necessary to explore the nature of the changes in PW activity found in this study and their linkage to SST anomalies.

Another potential indication on whether the 1960/1970s trend in wave fluxes and the BDC are deterministic or not could be if we find a similar signal in simulations with other model systems but with the same underlying SSTs or even in observational data. In Austin et al. (2007), three ensemble members of a simulation using observed SSTs show little changes in age of air form 1960 to 1980, but a rapid decrease after 1980 (consistent with an increase in the BDC). Also, the ensemble members agree reasonably well in the time evolution of upwelling. The problem in trying to identify trends in upwelling directly from measurements is the insufficient data basis for analysing global stratospheric dynamics before 1979. Especially direct measures of the meridional circulation (such as tropical upwelling), in which we find the strongest signal of the trend reversal (Fig. 10), are not easily available. The BDC causes diabatic warming in high latitudes and cooling in low latitudes, so that changes in the strength of the BDC are reflected in temperature time series (apparent in Fig. 9). A consistent data set of stratospheric temperatures (only for the Northern Hemisphere) that starts in 1957 and covers the time period to 2001 are the so-called Berlin analyses (Labitzke and collaborators, 2002, available at: http://badc.nerc.ac.uk/data/berlin_strat). Labitzke and Kunze (2005) presented trend calculations for temperature at high latitudes $\left(80^{\circ} \mathrm{N}\right)$ at $50 \mathrm{hPa}$ from the Berlin data set and two reanalysis data sets, which is comparable to the temperature trends in our Fig. 9. They found trends with opposite sign for the period 1964-1979 than for 1979-2000, but the trends are mostly not statistically significant. However, the high internal variability in northern high latitudes makes it difficult to find a significant signal in temperature time series, both in the model and in the observational data. Another study, based among other on ECMWF and NCEP reanalysis data, points out a clear reverse of trends around 1980 in the duration of easterlies in the stratosphere during summer (the so-called summer length) and attributed it to changes in wave activity (Offermann et al., 2005). However, direct comparisons of the same diagnostics from these observational studies did not show the same behaviour in the model simulation, which could indicate that the model system is responding to the observed SST anomalies in a different way than the real atmosphere. Since the SSTs are prescribed in the model, the interaction between ocean and atmosphere is an one-way only process, so that feedbacks of the atmosphere acting to drive the SST anomalies are not included. So even if the trends in the 1960/1970s are deterministic in the model, the response in the model could well be of different nature.

The intention of this study was to assess the uncertainty in the projections of atmospheric quantities introduced by the uncertainty in the boundary conditions, in particular in the SSTs. Since current chemistry-climate models are commonly not coupled to an interactive ocean, the simulations are subject to the use of prescribed SST data sets. For future projections, the only choice is to use projected SSTs from a Climate Model with an interactively coupled ocean. The projection of SSTs will never coincide exactly with the real future development of the SSTs. This is due to our limited ability to model the climate system and in addition to the fact that the climate system is chaotic (i.e. a small change in the initial conditions can lead to different realisation of the future). So even if the models were able to resemble the climatological state and the variance of the atmosphere-ocean system of the real world in an exact way, there would still be differences in the year-to-year variability. It is possible to assess the differences in climatologies and variance between the modelled SSTs and the observed SSTs for the past, but obviously not for the future. However, let us assume that the understanding of the climate system, and therefore the ability of modelling it, will apply in the same way to the future as to the past. In that case the difference between the modelled SSTs and the SSTs emerging in reality will be roughly similar in the future than in the past, both in terms of climatologies and variability. The term variability includes both the general variance, and the random year-to-year variability. By analysing the dependency of trends in atmospheric quantities on the prescribed SST data set, an estimate of the uncertainty in the trends due to uncertainties in the SSTs can be gained for the past. With the above assumption the uncertainty can be inferred to be similar in the future. As discussed earlier in the conclusions, the deficit of only having one ensemble member of each model simulation available inhibits the contribution of the differences found in the trends to SST differences. The results can rather be seen as tests of robustness of the trends both against the SSTs and the internal variability.

The results of this study show that in spite of the large differences in climatologies, the long-term trends in temperature and ozone are robust against the use of a different SST data set. Only on decadal time scales, trends are modulated by differences in the development of the SSTs. This suggests that trends in stratospheric temperature and ozone are largely driven by changes in concentrations of GHGs and ozone depleting substances, and are altered by SSTs only secondarily. 
The SST signal appears to be communicated to the stratosphere by modulation of PW activity and therefore the BDC. This implies that trends in these quantities are particularly sensitive to changes in SSTs, and the trend in tropical upwelling is found not to be robust before 1980 .

Acknowledgements. This study was funded by the European Commission through the SCOUT-O3 project under the 6th Framework Programme. The HadGEM1 data were provided by the Met Office Hadley Centre. We thank V. Grewe, M. Ponater and the three anonymous reviewer for helpful comments.

Edited by: P. Haynes

\section{References}

Andrews, D., Holton, J., and Leovy, C.: Middle Atmosphere Dynamics, Academic Press, San Diego, California, 1987.

Austin, J., Wilson, J., Li, F., and Vömel, H.: Evolution of Water Vapor Concentrations and Stratospheric Age of Air in Coupled Chemistry-Climate Model Simulations, J. Atmos. Sci., 64, 905921, 2007.

Bodeker, G. E., Garny, H., Smale, D., Dameris, M., and Deckert, R.: The 1985 Southern Hemisphere mid-latitude total column ozone anomaly, Atmos. Chem. Phys., 7, 5625-5637, 2007, http://www.atmos-chem-phys.net/7/5625/2007/.

Braesicke, P. and Pyle, J.: Sensitivity of dynmaics and ozone to different representations of SSTs in the Unified Model, Q. J. Roy. Meteor. Soc., 130, 2033-2045, 2004.

Butchart, N., Scaife, A., Bourqui, M., de Grandpre, J., Hare, S., Kettleborough, J., Langematz, U., Manzini, E., Sassi, F., Shibata, K., Shindell, D., and Sigmond, M.: Simulations of anthropogenic change in the strength of the Brewer-Dobson circulation, Clim. Dynam., 27, 727-741, 2006.

Charney, J. G. and Drazin, P. G.: Propagation of planetary-scale disturbances from the lower into the upper atmosphere, J. Geophys. Res., 66, 83-109, 1961.

Clarke, A. J. and Kim, K.-Y.: On Weak Zonally Symmetric ENSO Atmospheric Heating and the Strong Zonally Symmetric ENSO Air Temperature Response., J. Atmos. Sci., 62, 2012-2022, 2005.

Dameris, M., Grewe, V., Ponater, M., Deckert, R., Eyring, V., Mager, F., Matthes, S., Schnadt, C., Stenke, A., Steil, B., Brühl, C., and Giorgetta, M. A.: Long-term changes and variability in a transient simulation with a chemistry-climate model employing realistic forcing, Atmos. Chem. Phys., 5, 2121-2145, 2005, http://www.atmos-chem-phys.net/5/2121/2005/.

Dameris, M., Matthes, S., Deckert, R., Grewe, V., and Ponater, M.: Solar cycle effect delays onset of ozone recovery, Geophys. Res. Lett., 33, L03806, doi:10.1029/2005GL024741, 2006.

Deckert, R. and Dameris, M.: Higher tropical SSTs strengthen the tropical upwelling via deep convection, Geophys. Res. Lett., 35, L10813, doi:10.1029/2008GL033719, 2008a.

Deckert, R. and Dameris, M.: From Ocean to Stratosphere, Science, 322, 53-55, 2008b.

Edmon, H. J., Hoskins, B. J., and McIntyre, M. E.: Eliassen-Palm cross sections for the troposphere, J. Atmos. Sci., 37, 2600-2616, 1980 .
Eyring, V., Harris, N. R. P., Rex, M., Shepherd, T. G., Fahey, D. W., Amanatidis, G. T., Austin, J., Chipperfield, M. P., Dameris, M., Forster, P. M. D. F., Gettelman, A., Graf, H. F., Nagashima, T., Newman, P. A., Pawson, S., Prather, M. J., Pyle, J. A., Salawitch, R. J., Santer, B. D., and Waugh, D. W.: A Strategy for ProcessOriented Validation of Coupled Chemistry Climate Models, Bull. Am. Soc., 86, 1117-1133, 2005.

Eyring, V., Chipperfield, M., Giorgetta, M., Kinnison, D. E., Manzini, E., Matthes, K., Newman, P., Pawson, S., Shepherd, T., and Waugh, D.: Overview of the New CCMVal Reference and Sensitivity Simulations in Support of Upcoming Ozone and Climate Assessments and Planned SPARC CCMVal, SPARC Newsletter, 30, 20-26, 2008.

Fusco, A. C. and Salby, M. L.: Interannual Variations of Total Ozone and Their Relationship to Variations of Planetary Wave Activity, J. Climate, 12, 1619-1629, 1999.

García-Herrera, R., Calvo, N., Garcia, R. R., and Giorgetta, M. A.: Propagation of ENSO temperature signals into the middle atmosphere: A comparison of two general circulation models and ERA-40 reanalysis data, J. Geophys. Res., 111, D06101, doi:10.1029/2005JD006061, 2006.

Garny, H., Bodeker, G. E., and Dameris, M.: Trends and variability in stratospheric mixing: 1979-2005, Atmos. Chem. Phys., 7, 5611-5624, 2007, http://www.atmos-chem-phys.net/7/5611/2007/.

Grewe, V.: The origin of ozone, Atmos. Chem. Phys., 6, 1495 1511, 2006, http://www.atmos-chem-phys.net/6/1495/2006/.

Hardiman, S. C., Butchart, N., Haynes, P. H., and Hare, S. H. E.: A note on forced versus internal variability of the stratosphere, Geophys. Res. Lett., 34, L12803, doi:10.1029/2007GL029726, 2007.

Haynes, P., Marks, C., McIntyre, M., Shepherd, T., and Shine, K.: On the "downward control" of extratropical diabatic circulations by eddy-induced mean zonal forces, J. Atmos. Sci., 48, 651-678, 1991.

Hein, R., Dameris, M., Schnadt, C., Land, C., Grewe, V., Köhler, I., Ponater, M., Sausen, R., B. Steil, B., Landgraf, J., and Brühl, C.: Results of an interactively coupled atmospheric chemistry general circulation model: Comparison with observations, Ann. Geophys., 19, 435-457, 2001, http://www.ann-geophys.net/19/435/2001/.

Holton, J. R.: An introduction to dynamic meteorology, International geophysics series, San Diego, New York: Academic Press, 4th edn., 2004.

Ineson, S. and Scaife, A. A.: The role of the stratosphere in the European climate response to El Niño, Nat. Geosci., 2, 32-36, 2009.

Jiang, X., Eichelberger, S. J., Hartmann, D., Shia, R., and Yung, Y.: Influence of Doubled $\mathrm{CO}_{2}$ on Ozone via Changes in the BrewerDobson Circulation, J. Atmos. Sci., 64, 2751-2755, 2007.

Johns, T. C., Durman, C. F., Banks, H. T., Roberts, M. J., McLaren, A. J., Ridley, J. K., Senior, C. A., Williams, K. D., Jones, A., Rickard, G. J., Cusack, S., Ingram, W. J., Crucifix, M., Sexton, D. M. H., Joshi, M. M., Dong, B.-W., Spencer, H., Hill, R. S. R., Gregory, J. M., Keen, A. B., Pardaens, A. K., Lowe, J. A., BodasSalcedo, A., Stark, S., and Searl, Y.: The New Hadley Centre Climate Model (HadGEM1): Evaluation of Coupled Simulations, J. Climate, 19, 1327-1353, 2006. 
Kodama, C., Iwasaki, T., Shibata, K., and Yukimoto, S.: Changes in the stratospheric mean meridional circulation due to increased $\mathrm{CO}_{2}$ : Radiation- and sea surface temperature-induced effects, J. Geophys. Res., 112, D16103, doi:10.1029/2006JD008219, 2007.

Kushnir, Y., Robinson, W. A., Bladé, I., Hall, N. M. J., Peng, S., and Sutton, R.: Atmospheric GCM Response to Extratropical SST Anomalies: Synthesis and Evaluation, J. Climate, 15, 22332256, 2002.

Labitzke, K. and collaborators: The Berlin stratospheric data series, Tech. rep., FU Berlin, 2002.

Labitzke, K. and Kunze, M.: Stratospheric temperatures over the Arctic: Comparison of three data sets, Meteorol. Z., 14, 65-74, 2005.

Land, C., Feichter, J., and Sausen, R.: Impact of vertical resolution on the transport of passive tracers in the ECHAM4 model, Tellus B, 54, 344-360, 2002.

Li, F., Austin, J., and Wilson, J.: The Strength of the Brewer Dobson Circulation in a Changing Climate: Coupled Chemistry Climate Model Simulations, J. Climate, 21, 40-47, 2008.

Manzini, E., Giorgetta, M., Esch, M., Kornblueh, L., and Roeckner, E.: The Influence of Sea Surface Temperatures on the Northern Winter Stratosphere: Ensemble Simulations with the MAECHAM5 Model, J. Climate, 19, 3863-3881, 2006.

Martin, G. M., Ringer, M. A., Pope, V. D., Jones, A., Dearden, C., and Hinton, T. J.: The Physical Properties of the Atmosphere in the New Hadley Centre Global Environmental Model (HadGEM1). Part I: Model Description and Global Climatology, J. Climate, 19, 1274-1301, 2006.

Meehl, G., Covey, C., Delworth, T., Latif, M., McAvaney, B., Mitchell, J., Stouffer, R., and Taylor, K.: THE WCRP CMIP3 Multimodel Dataset: A New Era in Climate Change Research., Bull. Am. Soc., 88, 1383-1394, 2007.

Newman, M.: Interannual to Decadal Predictability of Tropical and North Pacific Sea Surface Temperatures, J. Climate, 20, 23332356, 2007.

Offermann, D., Jarisch, M., Donner, M., Oberheide, J., Wohltmann, I., Garcia, R., Marsh, D., Naujokat, B., and Winkler, P.: Middle atmosphere summer duration as an indicator of long-term circulation changes, Adv. Space Res., 35, 1416-1422, 2005.

Peng, S. and Whitaker, J. S.: Mechanisms Determining the Atmospheric Response to Midlatitude SST Anomalies., J. Climate, 12, 1393-1408, 1999.

Peng, S., Mysak, L. A., Ritchie, H., Derome, J., and Dugas, B.: The Differences between Early and Midwinter Atmospheric Responses to Sea Surface Temperature Anomalies in the Northwest Atlantic, J. Climate, 8, 137-157, 1995.

Randel, W., Wu, F., and Stolarski, R.: Changes in column ozone correlated with the stratospheric EP flux, J. Meteorol. Soc. Jpn., 80, 849-862, 2002.

Randel, W. J. and Held, I. M.: Phase Speed Spectra of Transient Eddy Fluxes and Critical Layer Absorption, J. Atmos. Sci., 48, 688-697, 1991.
Randel, W. J., Garcia, R. R., and Wu, F.: Time-Dependent Upwelling in the Tropical Lower Stratosphere Estimated from the Zonal-Mean Momentum Budget, J. Atmos. Sci., 59, 2141-2152, 2002.

Rayner, N. A., Parker, D. E., Horton, E. B., Folland, C. K., Alexander, L. V., Rowell, D. P., Kent, E. C., and Kaplan, A.: Global Analyses of sea surface temperatures, sea ice, and night marine air temperature since the late nineteenth century, J. Geophys. Res., 108, 4407, doi:10.1029/2002JD002670, 2003.

Reithmeier, C. and Sausen, R.: ATTILA: atmospheric tracer transport in a Lagrangian model, Tellus B, 54, 278-299, 2002.

Rosenlof, K. H. and Reid, G. C.: Trends in the temperature and water vapor content of the tropical lower stratosphere: Sea surface connection, J. Geophys. Res., 113, D06107, doi:10.1029/2007JD009109, 2008.

Sassi, F., Kinnison, D., Boville, B., Garcia, R., and Roble, R.: Effect of El-Nino Southern Oscillation on the dynamical, thermal and chemical structure of the middle atmosphere, J. Geophys. Res., 109, D17108, doi:10.1029/2003JD004434, 2004.

Seidel, D. J. and Randel, W. J.: Recent widening of the tropical belt: Evidence from tropopause observations, J. Geophys. Res., 112, D20113, doi:10.1029/2007JD008861, 2007.

Steil, B., Dameris, M., Brühl, C., Crutzen, P. J., Grewe, V., Ponater, M., and Sausen, R.: Development of a chemistry module for GCMs: first results of a multiannual integration, Ann. Geophys., 16, 205-228, 1998, http://www.ann-geophys.net/16/205/1998/.

Steinbrecht, W., Haßler, B., Brühl, C., Dameris, M., Giorgetta, M. A., Grewe, V., Manzini, E., Matthes, S., Schnadt, C., Steil, B., and Winkler, P.: Interannual variation patterns of total ozone and lower stratospheric temperature in observations and model simulations, Atmos. Chem. Phys., 6, 349-374, 2006, http://www.atmos-chem-phys.net/6/349/2006/.

Stenke, A., Grewe, V., and Ponater, M.: Lagrangian transport of water vapour and cloud water in the ECHAM4 GCM and its impact on the cold bias, Clim. Dynam., 31, 491-506, 2008.

Stenke, A., Dameris, M., Grewe, V., and Garny, H.: Implications of Lagrangian transport for simulations with a coupled chemistryclimate model, Atmos. Chem. Phys., 9, 5489-5504, 2009, http://www.atmos-chem-phys.net/9/5489/2009/.

Stott, P., Jones, G., Lowe, J., Thorne, P., Durman, C., Johns, T., and Thelen, J.-C.: Transient Climate Simulations with the HadGEM1 Climate Model: Causes of Past Warming and Future Climate Change, J. Climate, 19, 2763-2782, 2006.

von Storch, H. and Zwiers, F. W.: Statistical Analysis in Climate Research, Cambridge, UK: Cambridge University Press, March 2002, ISBN 0521012309, 2002.

WMO: Scientific Assessment of Ozone Depletion: 2006, Tech. rep., WMO Global Ozone Research and Monitoring Project Report No. 50, 2007.

Yulaeva, E. and Wallace, J. M.: The Signature of ENSO in Global Temperature and Precipitation Fields Derived from the Microwave Sounding Unit, J. Climate, 7, 1719-1736, 1994. 